\title{
Student Perceptions Regarding the Mind Map Application in Mathematical Education
}

\author{
Violeta Cvetkoska
}

Ss. Cyril and Methodius University in Skopje, Faculty of Economics - Skopje, Republic of Macedonia

\section{Abstract}

The aim of this paper is to observe the respondents' (second-year students') perceptions regarding the mind map tool application in the classes of the course Mathematical Methods, and with its application to learn the course material. A survey was conducted for this research. Based on the respondents' answers, 11 uses of the mind map tool application in teaching and 12 uses in learning the material have been determined. Besides its uses, 3 limitations of this tool have also been found. Introducing mind map in teaching the course Mathematical Methods was suitable for almost all respondents (with the exception of one respondent). Homework - making a summarized mind map for a particular chapter, was helpful for learning the material of that chapter for almost all respondents, except for one. Besides this, it has also been determined that the majority of the respondents would like to use this tool in other courses as well.

Keywords: teaching, learning, students, mind mapping, mind map JEL classification: C6, C83, 123

\section{Introduction}

Every organization needs people with quality education and knowledge, who continuously build up their existing knowledge, who think creatively, and who can find solutions to the problems they face. The intellect (ability to understand and insight) of every employee is the most valuable resource of an organization. But who is responsible for the intellect of the pupil or student that will one day apply for a certain work position? - Every person who is part of the teaching staff in educational institutions is in fact responsible for the intellect of the pupil or student. People should learn thoroughly and by understanding, in order to apply what they have learned, and also their creativity should be developed. Buzan et al. (2012) note that the percentage of creativity we exploit in kindergarten, elementary school, high school and as fully-fledged adults decreases; therefore, in kindergarten we function with $95 \%$ of our creativity, whereas as fully-fledged adults we function with $10 \%$. This percentage decrease is a result of the educational system, which does not contain and consequently apply appropriate techniques.

Taking and making standard linear notes lead to forgetting what is being learned. Why does this happen? - Because the brain does not function in a linear manner, but in a radiant one (Buzan et al., 2005). The presentations that contain full-length sentences from the material, with text only, by using only one color are monotonous and students think only about how much material is left. In order to keep the students' attention in class, learn the material with understanding, and foster their thinking and creativity, appropriate techniques and tools should be applied. Personally, I felt motivated to introduce mind mapping and the mind map tool in my classes in the course Mathematical Methods in the academic year 2014/2015. The 
course Mathematical Methods is an obligatory course for the second-year students of the Department of Accounting and Auditing (Ss. Cyril and Methodius University in Skopje, Faculty of Economics - Skopje).

Tony Buzan has developed mind mapping and the mind map tool. According to Buzan (1976), mind mapping uses both brain hemispheres. The left hemisphere is responsible mainly for the following abilities: words, numbers, logic, series, linearity, analysis and lists, whereas the right hemisphere is responsible for: rhythm, threedimensionality, imagination, color, orientation and gestalt. Mind mapping provides visual thinking, and considering the fact that the brain functions in a radiant manner (not in a linear one), a mind map represents a visual diagram in which information is structured in such a manner. Mind maps contain key words instead of whole phrases and full sentences, as well as lines, colors, symbols and images. For mind mapping there are laws and recommendations which are explained in detail in (Buzan et al., 2005, pp. 87-103), and the steps for making a mind map are given in Cvetkoska (2015, pp. 671-672). The mind map tool is used by millions around the world, and in the focus of this paper is its application in mathematical education.

Brinkmann (2003a) explains mind mapping, discusses its applications in mathematical education, and states its advantages and limitations. According to Brinkmann (2003a, pp. 98-99), mind maps can be applied in mathematical education to help in the organization of information, in using it as a memory aid, in facilitating unit repetition, in connecting newly-acquired and previously-learned concepts, introducing new concepts in classes, fostering students' creativity and demonstrating connections between concepts that are mathematical and those that are not.

Brinkmann (2003b) presents the methods of mind mapping and concept mapping as pedagogical tools suitable in mathematical education. This paper covers their possible applications and discusses the advantages and limitations of both methods.

In Entrekin's paper (1992), mind mapping is used in mathematics classes as a summarized task for the material previously presented by the teacher. The teacher asks the questions, the students provide answers, and the map expands as answers are added to it. Hence, more interaction among the students is allowed and less teacher inclusion. As in Entrekin's paper, this paper employs a summarized mind map for the purpose of chapter repetition. During the introductory lecture for the course Mathematical Methods in the summer semester 2014/2015, it was explained to the students that this tool will be applied for repetition at the end of each chapter. The teacher writes the title of the chapter in the middle of the board, draws the main branches and asks questions, and so by adding the students' answers the map slowly develops and increases in size. One of the main branches of every map includes successful stories from existing companies in the world which have applied the models and methods that are part of the chapter. In addition, they were told that after each chapter repetition, through drawing a summarized mind map, they would be given a homework assignment - to make their own mind map for the chapter. The students were introduced to the concept of mind mapping and how to make a mind map was presented and explained. In order to observe their perceptions of the mind map tool application in teaching and learning the material, a survey was conducted by distributing a questionnaire.

In this paper, following the introduction, special attention is paid to the methodology, after which the gained answers from the respondents are presented and discussed, with the conclusion at the end. 


\section{Methodology}

During the introductory lecture of the course Mathematical Methods it was determined that out of 144 students present, only 2 of them had heard about the concept of mind mapping ( 1 of them had heard of it in high school, and the other student at a seminar), whereas only 1 student had heard about the mind map tool (at a seminar). Furthermore, the students had not used the tool in the other courses at Faculty, but only 1 student made his own mind maps in the following courses: Organizational Behavior, Statistics, Costs Accounting, and Financial Accounting.

A survey was conducted for the purpose of observing students' perceptions in the mind map tool application in teaching and learning the material for the course Mathematical Methods.

The questionnaire consists of 8 questions intended to determine whether the respondents consider the introduction of the mind map tool in teaching Mathematical Methods as suitable; to determine the uses of the application of this tool in teaching and learning the material; to determine whether the respondents find any limitations to the mind map tool, and if confirmed then they should specify them; to determine whether the homework assignment (making a summarized mind map for a certain chapter) helps the respondents in learning the material of that chapter; to determine whether the respondents support the use of this tool in chapter repetition for the second mid-term test, as well as to determine whether they want to use the mind map tool in other courses at the Faculty.

The sample was comprised of students that had the course Mathematical Methods in the summer semester 2014/2015. The questionnaire was distributed among the teaching classes before the start of the first mid-term week, in March 2015, to 152 students present, and each of them filled in the questionnaire anonymously. The following section presents the results of the survey.

\section{Results}

The questionnaire, which was distributed among 152 respondents, was fully completed by 76 of them. This section presents and analyzes the results acquired from the fully completed questionnaires.

According to 75 respondents, the introduction of the mind map tool in Mathematical Methods classes is suitable, whereas only 1 respondent considered it to be unsuitable.

The following uses of the mind map tool application in teaching the course Mathematical Methods have been determined:

- Improved memory (68 respondents noted such);

- The most important points from each chapter are clearly summarized (43 respondents);

- It serves as a learning guide (25 respondents);

- An interesting way to repeat each chapter (22 respondents);

- The material from each chapter is understood better (20 respondents);

- An interesting approach towards the material (12 respondents);

- Improved student interest (8 respondents);

- It fosters thinking (7 respondents);

- It fosters creativity (5 respondents);

- It keeps students' attention (4 respondents);

- Enables class interaction (4 respondents).

Figure 1 presents a mind map for the uses of application of this tool in teaching 
the course Mathematical Methods. This Figure has been made by using the iMindMap Software (Software iMindMap, 2017).

Figure 1

Mind Map - uses in teaching the course Mathematical Methods

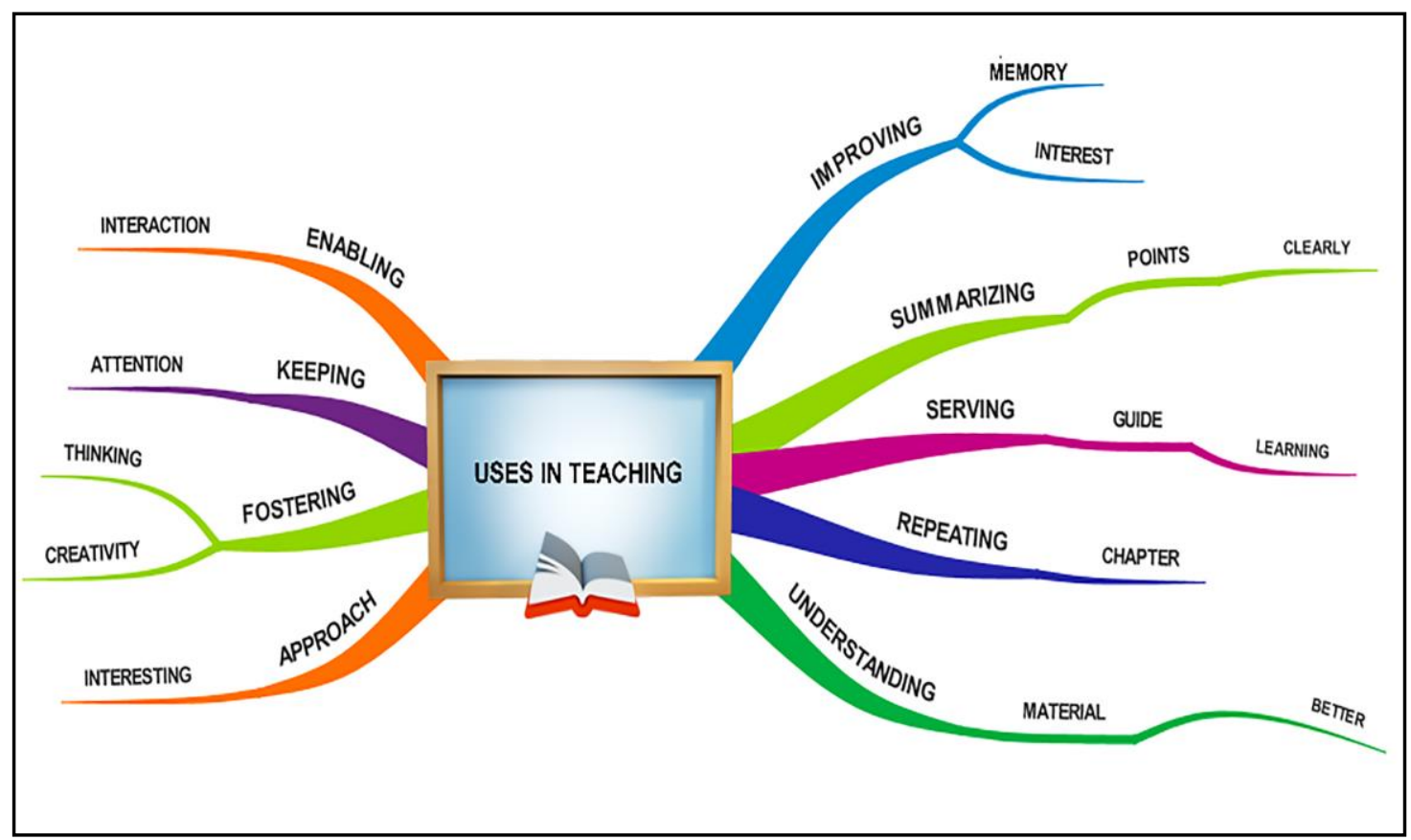

Besides the uses of the mind map tool in Mathematical Methods classes, the following uses regarding its application in learning the material for this course have been determined:

- The material from each chapter is acquired more easily $(62$ respondents noted such);

- The most important points from each chapter are clearly summarized (34 respondents);

- The material is learned by understanding (24 respondents);

- Learning becomes more interesting (a figure of each chapter is made) (18 respondents);

- The material is repeated much faster (18 respondents);

- The material remains memorized (15 respondents);

- It is a good reminder (12 respondents);

- For achieving better results (5 respondents);

- It fosters thinking (4 respondents);

- It fosters creativity (2 respondents);

- The possibility for leaving our own mark (1 respondent);

- It helps when solving tasks (the steps of an algorithm can be presented through a mind map) (1 respondent).

According to 71 respondents, the mind map tool has no limitations, whereas only 5 respondents stated that it did have limitations; 3 of them noted that some points could not be summarized in one word, 1 participant noted that strictly-defined points could not be remembered, and 1 other participant noted that it was difficult to present relations between distant branches. 
When making a mind map it is suggested for only one key word for each branch to be used so that the key words of the main branches contain the most associations and the map can be developed infinitely, whereas by using arrows information that is placed on different branches can be connected. For why it is important to use key words when making a mind map see (Howe, 1970; Tipper, 2008).

The homework assignment given by the teacher, which consisted of making a summarized mind map for a certain chapter, helped 75 respondents learn the chapter. According to 75 respondents the mind map tool should be used in teaching, when repeating each of the chapters that are to be included in the second mid-term test. In addition, it was determined that 69 respondents would like to use the mind map tool for the rest of the courses at the Faculty, but 7 participants were not enthusiasts regarding that option.

\section{Discussion}

In this paper, research was conducted via a survey given to second-year students who had the course Mathematical Methods in the summer semester 2014/2015, and its purpose was to determine their perceptions regarding the mind map tool application in the classes of this course, and through its application to learn the course material.

Regarding the application of the mind map tool in teaching there have been identified 11 uses. The most commonly stated use is improved memory, followed by: the most important points from each chapter being clearly summarized; serving as a learning guide; an interesting way to repeat each chapter; the material from each chapter is understood better; an interesting approach towards the material; for improving student interest; fostering thinking and creativity; keeping students' attention; and providing class interaction.

Besides the uses of the mind map tool application in teaching the course Mathematical Methods, 12 uses have also been identified regarding its application in learning the course material. The use that has been mentioned the most is that the material from each chapter is acquired more easily, followed by: the most important points from each chapter being clearly summarized; the material is learned by understanding; the learning process becomes more interesting; the material is repeated much faster; the material remains memorized; it helps when trying to revise the material; for achieving better results; it fosters thinking and creativity; the possibility for leaving their own mark; and it helps when solving tasks.

For $7 \%$ of the participants, the mind map tool also has limitations: some points cannot be summarized in one word; strictly-defined points cannot be remembered; and it is difficult to present relations between distant branches.

Tony Buzan, who has developed mind mapping and the mind map tool, recommends only one key word to be used in each branch, so that the key words in the main branches are those that contain the most associations, and considering the infinite associative nature of our brain, the map can thus be developed infinitely. By using only one key word in each branch, and not phrases or full sentences, the key words can be remembered much easily, and the use of the arrows provides the connection of information that is found in different map branches.

Besides the students' perceptions regarding the use of the mind map tool in teaching and learning the course Mathematical Methods, my personal views are that this tool provided a new and stimulating approach to the material, the students attended classes more and were more attentive, they continuously learned the material and were prepared to answer any posed question when a summarized mind map for a chapter was being drawn on the board. In addition, the homework 
assignment that was given to the students (making their own summarized mind map of the material from the class) allowed for strengthening their knowledge and instigating their creativity. They developed the skill of creating mind maps and each summarized mind map was better than the previous.

Each student has their own learning style, but the mind map tool is suitable for each style because it makes the process of learning easier, it can easily be mastered (making a mind map manually or using the iMindMap software) and it can be used for separate lessons as well, not only for a whole chapter.

\section{Conclusion}

The aim of this paper was to observe the respondents' perceptions (second-year students at the Department of Accounting and Auditing, Ss. Cyril and Methodius University, Faculty of Economics - Skopje) regarding the mind map tool application in classes in the course Mathematical Methods in the summer semester 2014/2015, and with its application to learn the course material. In achieving this aim, a questionnaire was prepared and distributed to the respondents. The questionnaire was fully answered by 76 respondents. On the basis of the respondents' answers, there have been identified uses regarding the application of the mind map in teaching (11 uses) and in learning the course material (12 uses). According to 5 participants there have been identified 3 limitations of the use of this tool regarding its application in mathematical education.

Based on the respondents' answers, the introduction of the mind map tool in the course Mathematical Methods is suitable for almost all of them (with the exception of only one respondent). Additionally, the given homework assignment - to make a summarized mind map of a certain chapter - helps with almost all of the respondents in learning the material of that chapter (with the exception of one respondent). Also it was found that 69 respondents would like to use the mind map in other courses at the Faculty.

The limitation of this study regards the small number of fully filled-in questionnaires by the respondents, but in my opinion there would be no significant differences in the obtained answers.

On the basis of my positive experience of using the mind map tool in teaching and learning the material by understanding, I suggest using this tool in educational institutions. I believe that the teaching staff in higher educational institutions should be acquainted with the benefits of application of the mind map tool in teaching, and they should be trained to apply it to make an annual teaching plan, as well as to use it for presentation and revision of the material.

The idea for my next research is based on gaining the opinions of the teaching staff who will be applying this tool in their day-to-day teaching, and also of the large number of students who will be using it in learning the material for their exams.

\section{References}

1. Brinkmann, A. (2003a), "Mind mapping as a tool in mathematics education", Mathematics Teacher, Vol. 96 No. 2, pp. 96-101.

2. Brinkmann, A. (2003b), "Graphical knowledge display - mind mapping and concept mapping as efficient tools in mathematics education", Mathematics Education Review, No. 16, pp. 35-48.

3. Buzan, T. (1976), Use Both Sides of Your Brain, New York, E. P. Dutton \& Co.

4. Buzan, T., Buzan, B. (2005), The Mind Map Book, Belgrade, FINESA (On Serbian)

5. Buzan, T., Griffiths, C., Harrison, J. (2012), Modern Mind Mapping for Smarter Thinking, Cardiff Bay, Proactive Press. 
6. Cretkoska, V. (2015), "Using the mind map tool in teaching and learning", Annual of the Faculty of Economics - Skopje, Faculty of Economics - Skopje, Skopje, Vol. 50, pp. 667-686 (on Macedonian).

7. Entrekin, V.S. (1992), "Mathematical mind mapping", Mathematics Teacher, Vol. 85 No. 6, pp. 444-445.

8. Howe, M. J. A. (1970), "Using students' notes to examine the role of the individual learner in acquiring meaningful course matter", Journal of Educational Research, Vol. 64, pp. 61-63.

9. Tipper, M. (2008), "Why Do I Have to Use Keywords When Mind Mapping? How To Use Keywords in Mind Maps", available at:

http://www.michaelonmindmapping.com/mind-maps/why-do-i-have-to-usekeywords-when-mind-mapping/ (12 June 2015)

10. Software iMindMap 10, available at: https://imindmap.com/software/ (4 May 2017)

\section{About the author}

Violeta Cvetkoska, PhD, is an Assistant Professor at Ss. Cyril and Methodius University in Skopje, Faculty of Economics - Skopje. She received her PhD in Economics at the Faculty of Economics - Skopje in 2013. Her main research interests are operational research and business analytics. She participates actively in conferences, symposia, seminars, training and workshops in the country and abroad. A special contribution to the development of her academic career has been the realized study visits at Universities in Europe and South America. She is an author and co-author of several papers published in international journals and conference proceedings, and her most recent authored work is: "Applying multi-criteria decision making methods in banking" (2017). She works on various projects and is a member of the Croatian Operational Research Society (CRORS) and in working groups of the Association of European Operational Research Societies (EURO). Author can be contacted at vcvetkoska@eccf.ukim.edu.mk. 